\title{
¿Escritura o pintura? Un debate humanista en el Perú colonial ${ }^{1}$
}

\author{
Fermín del Pino Díaz
}

\section{RESUMEN}

Se ofrece un examen crítico de las posiciones que niegan el valor superior de la escritura alfabética, apoyado desde el humanismo clasicista (lingüística y etnográficamente), y en particular desde el argumento del P. Acosta sobre los diversos sistemas de

1 Leído en el simposio internacional La cultura del libro: aproximaciones desde la historia y el arte, patrocinado por la Biblioteca Nacional del Perú, Lima, agosto de 2013. Agradezco a Ramón Mujica la ocasión de participar en él y la invitación posterior a dedicar un recuerdo a Sabine MacCormack. La enorme familiaridad de Sabine con el mundo romano y con los misioneros como Acosta le permitirían apreciar este esfuerzo. De hecho, un temprano ensayo mío de los años 80 sobre el clasicismo de Acosta, destinado a formar parte de una serie alemana sobre el Humanismo y el Nuevo Mundo fue traducido al inglés por ella, a petición mía, aunque luego se frustró su publicación. Posteriormente, sus numerosos ensayos sobre Roma y Perú me han servido de constante incitación intelectual. 
memoria indianos. Para mostrar la posición indigenista del P. Acosta, se usan los testimonios del autor y de sus seguidores, en particular del Inca Garcilaso. Se ofrece asimismo una reflexión sobre el valor de la lingüística.

Palabras clave: José de Acosta, Inca Garcilaso de la Vega, Guamán Poma, Blas Valera, Historia de la Etnografia

\section{Abstract}

The author offers a critical examination of the positions which deny the superior value of alphabetic writing, supported by the Classical humanism (linguistic and ethnographically), and in particular by the views of Fr. Acosta on various Indian memory systems. To show by the indigenist position of Fr. Acosta, the testimony of the author and his followers, in particular Inca Garcilaso, is mentioned.

Keywords: José de Acosta, Inca Garcilaso de la Vega, Guamán Poma, Blas Valera, History of the Etnography

\section{Relevancia insospechada de las Humanidades}

COMO ES BIEN SABIDO, la cultura escrita constituyó para los humanistas uno de los fundamentos de su identidad intelectual. En general, los llamados entonces estudios de humanidades suelen hoy confundirse también con los estudios literarios o, más frecuentemente, con los tradicionales estudios universitarios conocidos como Filosofía y letras, por oposición a las especialidades derivadas de las ciencias (matemáticas, física, química, ciencias naturales, etc.). Proponemos que no se confunda ese sentido actual del término con el que tuvo entonces: se trataba más bien de un modo innovador de concebir el mundo y el saber, basado precisamente en la lectura directa y el comentario crítico de textos y monumentos clásicos. Este nuevo programa de estudios significaba una verdadera revolución que no 
siempre hemos valorado bien sus herederos posteriores, ni a veces hemos percibido siquiera cómo era realmente.

Lo que define este movimiento intelectual que estuvo vigente a comienzos de la edad moderna (especialmente en Italia, Países Bajos, Alemania, Francia, Portugal, Inglaterra y España) no es que se cultivasen los estudios literarios en sí mismos, sino que se les adoptase como base del mundo presente, desde una nueva concepción global: una vez establecido como paradigma generacional cristiano, un modelo cultural ideal (clásico pero compatible con el presente cristiano), los humanistas podían desde él asomarse al mundo propio y podían construir entonces un «mundo nuevo» por comparación con el conocido hasta ese momento. No se trataba solamente de leer a los autores antiguos o de acceder a nuevas versiones textuales de los mismos (aunque efectivamente se descubrieron entonces nuevos textos de autores clásicos como Cicerón o Virgilio e, incluso, de Aristóteles o Platón), sino de hacerlo de un modo más sistemático, con un nuevo espíritu pedagógico y con una nueva función moral. Ese mundo ideal informaba ahora completamente la cultura, pues se refería no solamente al campo de los estudios históricos, literarios y estéticos, sino a todo el ámbito de la cultura (a la política y a la moral, a las devociones e, incluso, a la tecnología).

Aunque no se suele subrayar, uno de los componentes esenciales de la cultura renacentista es la utopía, que se basaba en el mito de una antigua Edad de Oro ubicada en el pasado clásico; y tal vez merezca la pena fijarse en esta asociación histórica entre utopía y humanismo para comprender ese elemento imaginario que tanto ha alimentado la sociedad andina, según la historiografía peruana contemporánea. La mayor parte de los autores que imaginaron entonces una reforma utópica para los problemas de su tiempo (como Francesco Petrarca, Thomas More, Guillaume Budé, Luis Vives o Erasmus Rotteradamus) eran deudos del sueño humanista. Así lo ha destacado no hace mucho Francisco Rico, profesor de la Uni- 
versidad de Barcelona, en su libro El sueño del humanismo (1993). ${ }^{2}$ Convencieron incluso a sus enemigos, los escolásticos, a usar más profesionalmente el saber clásico, y de ahí derivó en parte la nueva escolástica hispana de Salamanca, liderada por Vitoria.

Podría añadirse a la lista de humanistas el nombre preclaro del Inca Garcilaso, cuyo componente utópico ha sido reconocido por ilustres garcilasistas, y cuya relación con el anticuarismo andaluz fue destacado hace tiempo por el crítico literario Eugenio Asensio (1953), con motivo de la publicación de dos cartas suyas (15921593) halladas por él en Lisboa. ${ }^{3}$ Esta correlación reiterada entre utopía moderna y mito revitalizado del mundo clásico vuelve a darse posteriormente en la Ilustración, que tanta importancia concedió a la cultura clásica: la única obra verdaderamente utópica escrita por un español en el siglo XVIII, aunque anónima, Sinapia (Avilés Fernández 1976; López 1990), se debe justamente al eximio latinista Manuel Martí, deán de Alicante y maestro del famoso ilustrado valenciano Gregorio Mayans. Digamos ahora, para esclarecer el valor de esta referencia puntual, que la conexión utópica del clasicismo se debe no tanto al supuesto componente utópico de la cultura clásica, sino a la función utópica actualizada que ella ejerce sobre los humanistas, al ofrecerles un contraste moral entre un pasado ajeno idealizado y un presente propio crítico. ${ }^{4}$

De hecho, la Ilustración reforzó aún más la referencia al mundo clásico no cristiano por parte de países cristianos, que pudieron superar así la nueva división surgida entre católicos y protestantes al inicio de la Edad moderna. No se ha destacado suficientemente la singularidad de este proceso secularizador de Occidente en la

2 Con sucesivas ediciones ampliadas hasta la definitiva (Rico 2002).

3 Para una actualización de esas relaciones eruditas del inca con los anticuarios, ver Bernand (2011).

4 Aún merece la pena revisar la obra antigua de Luis Díez del Corral (1957). He tratado de ello más detenidamente en mi ensayo sobre los paremiólogos humanistas (Del Pino 2002). 
historia de la humanidad, pero lo cierto es que no ha ocurrido del mismo modo en otros ámbitos culturales, especialmente en el mundo oriental. Como ya planteó el investigador alemán Wolfgang Reinhard, en un brillante artículo de 1987 (que no ha tenido la difusión que merece), es útil comparar el colonialismo cristiano con otros (islámico, hindú y chino). Concluía reflexionando sobre la compartida simultaneidad imperial entre la conquista del mundo y la conquista de la lengua, aunque la diferencia fundamental entre los colonialismos existentes derivaba de que solamente el cristiano admitió traducir su libro sagrado a otras lenguas, y se interesó suficientemente por esas otras culturas como para querer comprenderlas:

Exégesis de textos sagrados hubo en otras partes, pero para el Corán o para los Vedas podía bastar una fidelidad a-histórica a la letra; no así con el cristianismo, porque no puede soslayar el problema de la diferencia histórica de los textos (...). No es que los europeos hayan pensado de una manera menos etnocéntrica que otros pero, a diferencia de los demás, hubo en el etnocentrismo europeo tradicional un alto grado de agilidad intelectual que les permitió entrar en lenguas y culturas extranjeras. ${ }^{5}$

No todos los analistas del colonialismo cristiano han tenido esta voluntad de diferenciarlo respecto de otros, destacando tanto los aspectos económico-políticos como los intelectuales y morales. Tal vez mirarse a sí mismo despiadadamente sea propio más bien de la tendencia autocrítica occidental, acusándose de que el contexto político y el afán de dominio propio sobre otros pueblos hubiese arriesgado de anular cualquier otra diferencia histórico-cultural en el mundo, que es a lo que se dirigía la crítica elaborada por Edward Said contra el campo completo del orientalismo occidental. En definitiva, sostenía este autor, el conocimiento occidental de Oriente lo que pretendía era dominarlo y usarlo en su beneficio, al simplificarlo y definirlo como lo contrario de sí mismo. Creo que si el profesor

5 Reinhard (1987). Agradezco a Lilia Frieiro la traducción, que fue consultada con el autor. 
palestino Edward Said no se hubiera educado en un ambiente norteamericano de hipercriticismo literario, tal vez no hubiera desarrollado su tesis en el sentido agonístico que lo hizo; aunque al final llegó a reconocer el error del mundo islámico en no adaptarse al sistema democrático y pacifista de laicismo occidental (como hiciera Nelson Mandela en Sudáfrica o, anteriormente, Gandhi en la India). En 1999, de acuerdo a este modelo sudafricano, fundó Said la Orquesta Diván Este-Oeste, junto con su amigo el músico argentinoisraelí Daniel Barenboim, una iniciativa para reunir cada verano a un grupo de jóvenes con talento procedentes tanto de Israel como de los países árabes; por ello, recibieron ambos en 2002 el Premio Príncipe de Asturias de la Concordia.

Si el triunfo secularizador del Occidente cristiano costó quince siglos de lucha contra el propio etnocentrismo (hasta llegar al humanismo y, dos siglos después, la Ilustración), debemos tener la misma paciencia con otros sistemas religiosos que comparten hoy el mundo. A cambio, deberíamos empezar practicando la caridad con nosotros mismos como sistema cultural, no cayendo en explicaciones reductoras de nuestra propia identidad. Pero, mientras tanto, la lección principal derivada de la comparación colonial es que, definitivamente, el etnocentrismo cultural impide siempre la tolerancia, interna y externa.

La misma versión reductora empleada con el orientalismo europeo ha ocurrido con el humanismo, que ha sufrido el mismo enfoque hipercrítico. De parte de una corriente que se conoce como «post-colonial» o «de-colonial» (y de la cual se había celebrado un congreso recién entonces en Lima) ${ }^{6}$ se ha desarrollado la misma interpretación contra el humanismo, reduciendo su identidad pro-

6 Simposio internacional sobre estudios decoloniales y postcoloniales en México y Perú: nuevos aportes a la teoría cultural latinoamericana. Se celebró el miércoles 7 de agosto del 2013, en el Instituto Raúl Porras Barrenechea de la Universidad Nacional Mayor de San Marcos. 
funda a sus meras conexiones e intereses de poder: se ha destacado del humanismo su carácter europo-céntrico, porque aupaba la cultura clásica del Mediterráneo (de Grecia y Roma) a un nivel paradigmático como modelo universal de cultura y criterio moral en el presente, debido que se dio principalmente en estos mismos países mediterráneos. Ésta ha sido la interpretación sostenida, entre otros, por el hispanista argentino Walter Mignolo en un libro suyo que podría titularse en español El lado oscuro del Renacimiento (1995), ' donde se muestra convencido de que la sobrevaloración de la cultura escrita es el lado oscuro de este porque infravalora las culturas sin escritura (o con otro tipo de escritura, por ejemplo, jeroglífica). Pero, como tendremos ocasión de ver con ejemplos peruanistas (a los que se refiere particularmente Mignolo), el humanismo europeo no impidió percibir los valores culturales del Nuevo Mundo, sino precisamente todo lo contrario. Nos basamos para empezar en una mera constatación estadística, ya que nunca se escribieron tantos informes etnográficos y gramáticas no europeas como desde 1492 especialmente de lenguas y culuras del Nuevo Mundo y particularmente por parte de la orden religiosa jesuita, la más cercana al movimiento humanista.

También nos queremos basar en otro argumento anterior al de Reinhard (justo treinta años antes del trabajo de Mignolo), descubierto por un eminente arqueólogo peruanista, el doctor John H. Rowe (1965). El aprecio de la cultura clásica por los humanistas italianos (a pesar de que se engendraba primeramente en una reacción nacionalista florentina frente al afrancesamiento de la corte papal en Avignon en el siglo XIV, lejos de su Roma querida) suponía en realidad una crítica a la cultura cristiana del presente (a su torpe uso del latín clásico, así como a los laxos conceptos morales y artísticos imperantes durante el largo medievo), incapaz de pro-

7 Parece que el autor no ha querido que se traduzca de su versión original en inglés. 
poner una reforma del modo de vida cristiano imperante. No es casual que dos de los críticos mayores de la Roma papal fueran dos humanistas paradigmáticos como Nicolás Maquiavelo y Erasmo de Rotterdam. El argumento del profesor Rowe, apoyándose en historiadores expertos como Arnaldo Momigliano y Erwin Panofski, es que fue esta crítica a la propia cultura cristiana la que propició una apertura a la cultura clásica del pasado, favoreciendo consecuentemente (he aquí la propuesta de Rowe) una apertura en el presente a otros modos no cristianos de cultura. Así, con esta superación del etnocentrismo cristiano, es como se explica Rowe la curiosidad por el Nuevo Mundo de personajes italianos como Pedro Mártir, nombrado primer cronista indiano por los Reyes Católicos gracias a su curiosidad americana o la nueva curiosidad por África de gentes como el marino italiano Alvise Cadamosto, una generación anterior a Colón.

Yo mismo pude comprobar en los años 70 -siguiendo la hipótesis de Rowe- el temprano interés por los nativos de la isla de Gran Canaria de parte de humanistas como Giovanni Boccaccio, hasta el punto de traducir al latín un reciente informe italiano de 1341 (titulado De Canaria et insulis reliquis ultra Ispaniam in occeano noviter repertis), que fue en muchos sentidos precursor de Pedro Mártir, e igualmente lleno de sensibilidad cultural ante el modo de vida primitivo de estos habitantes (Del Pino 1976). Creo con el doctor Rowe que este interés excepcional de Boccaccio por los canarios se explica mejor como una curiosidad personal suscitada especialmente por las noticias romanas acerca de sus propios primitivos: fundamentalmente Heródoto y Tácito, que no fueron creídos en su tiempo por exagerar las virtudes de las otras culturas (persas y germanos) $y$, sin embargo, fueron nuevamente apreciados como testigos veraces precisamente a partir del Renacimiento. Es conocida la curiosidad de Boccaccio hacia la tradición clásica, junto con Petrarca como muestra claramente el refinado latín usado para este informe. Efectivamente fue este lenguaje y saber antiguo, vuelto a 
la actualidad con prestigio renovado, el que ayudó a los humanistas italianos a percibir el interés por las diferencias en el presente, y no les consintió permanecer indiferentes ante las novedades de otros mundos, derivadas en gran parte de los viajes crecientes: los cuales fueron asimismo propiciados por el avance de los conocimientos geográficos derivados del humanismo (brújula, velamen, embarcaciones, mapas, sistema de vientos, etc.).

Admito que esta visión sobre las ventajas a favor del reconocimiento de la alteridad cultural por parte del Renacimiento es tal vez optimista, por comparación con la actitud hacia el exterior de otros colonialismos (persa, chino, hindú, mongol, islámico, etc.). El propio Rowe (1965: 2) advertía que el origen de la temprana tolerancia intercultural de Herodoto hacia los persas provenía más bien de fuente persa, puesto que los griegos le tenían por mentiroso en este punto. Sólo recientemente hemos recibido una información puntual en la historia global de otros pensamientos interculturales no occidentales, de parte del intelectual indio Sanjai Subramanyam, cuyo conocimiento políglota y su familiaridad con los imperios portugués e inglés en Asia nos ha ilustrado repetidamente en este aspecto, antes poco conocido. ${ }^{8}$ El Renacimiento puso poco interés en atender al mundo islámico tras la toma de Constantinopla, aunque algo se supo del mundo indio, persa y chino a través de viajeros europeos como Marco Polo y los posteriores viajeros laicos y religiosos (especialmente jesuitas). Insistiendo en una visión crítica de los recientes estudios globales y enfatizando igualmente los ámbitos ibéricos, debemos señalar el interés de algunos textos recientes de Serge Gruzinski (2001, 2004 y 2006), en cierta continuidad con Su-

8 Puede accederse a su lección inaugural en el Collége de France, dictada en noviembre de 2013 desde su cátedra Histoire globale de la première modernité. Fue publicada con el título Aux origines de l'bistoire globale (París, Fayard, Collège de France, coll. «Leçons inaugurales», 2014, 63p.). Accesible en http://books.openedition.org/cdf/3599. En castellano está disponible desde 2006 su artículo comparativo sobre el imperio español y portugués. 
bramanyam, en cuanto sostiene la modernidad de la temprana mundialización ibérica y se refiere no tanto a una aculturación europea del resto del mundo sino a la pervivencia de su original pluralidad, dentro de un mestizaje y conectividad cultural creciente.

\section{ESCRITURA Y PINTURA}

Lo que nos interesa ahora no es el movimiento humanista como tal, en sí mismo, sino una consecuencia derivada de él, la importancia atribuida a la cultura escrita: es decir, la sobrevaloración de la escritura, a través de la cual se había conservado principalmente la tradición clásica. ¿Se tratará tal vez de cierta especie de magia simpática por parte humanista, que le llevó a confundir el medio -la escritura- en que se le transmitió la cultura antigua con aquella misma? Lo cierto es que fue la admiración por una cultura ajena, específicamente no cristiana, la que le permitió al humanista (que, no se olvide, es solo un mero reformista de la tradición cristiana medieval, no un intelectual laico moderno) esbozar una mirada crítica sobre el propio pasado, esperando quizás una solución a sus propias carencias venida del exterior.

Esa esperanza de nueva vida futura por parte del humanista se basaba en una mirada áurea y utópica del pasado clásico, donde desaparecían todas sus desgracias y medianías cotidianas. El pasado grecorromano fue visto por los humanistas cristianos como ideal lejano - no cercano- porque pudieron superar la inveterada tradición medieval, que se veía a sí misma como continuadora ininterrumpida del pasado clásico. Se abría de nuevo a los ojos renacentistas el pasado, por obra y gracia de una nueva sensación de distancia cultural que había ocultado el mundo medieval que no veía distancia alguna entre sí y el pasado clásico: por ejemplo, a Alejandro Magno se le representaba con vestidos medievales, como si fuese coetáneo. Esta nueva cercanía del pasado lejano operaba como el mito de Incarri 
andino, dando significado nuevo y trascendente a su propia tradición y a toda su venerable antigüedad, ya marchita: así la resurrección futura del cuerpo del rey Inca (anunciada por los cristianos) va a constituir para el hombre andino, destruido demográficamente por la conquista cristiana, la esperanza de una compensación apropiada. Resurrección imprevista en un inesperado futuro prometedor (Incarri), que fue predicado ya por los propios misioneros que asistieron a la ejecución de Topa Amaro, para consuelo de los deprimidos testigos del acto; pero que nada tenía que ver con sus previas expectativas tradicionales, donde la resurrección no contaba (por eso se cuidaban tanto los servidores cusqueños de que no se pudriesen los restos mortales incas y que ni siquiera se perdiesen sus cabellos y uñas).

Esta novedad andina de la resurrección (lo mismo que el concepto de distancia cultural con el mundo clásico, renacido de nuevo para los humanistas) era en parte un descubrimiento real, y en otra parte una invención virtual que requería retoques y mediaciones para lograr el ajuste. Cuando los humanistas quisieron explicarse otras culturas contemporáneas como igualmente legítimas incurrían en una deformación frecuente, porque tendían a romanizarlas, a verlas por el modelo conocido de una cultura clásica. Si hacían una gramática del nuevo lenguaje americano, tendían a ver fenómenos encontrados en la gramática latina, única existente hasta el momento. Cuando Nebrija se propuso traducir al castellano su gramática, sus Introductiones latinae (Salamanca, 1481), a petición de la reina Isabel (que quería se le enseñara el latín, en castellano, a las señoras de su corte), halló sorprendido que los ejemplos gramaticales y las partes castellanas de la misma eran muy parecidos a la latina. De ahí nació la idea de elaborar una gramática castellana, por sugerencia del humanista y asesor real fray Hernando de Talavera, y así tuvo que explicarlo a la sorprendida reina en 1492, diciendo aquello tan repetido de que «la lengua es compañera del imperio» (cuando aún no se había descubierto el Nuevo Mundo). No es el momento de discutir si, dado el 
proyecto nacionalista de los Reyes Católicos, la referencia de Nebrija al imperio quería decir que la gramática castellana era realmente necesaria con ese fin. En todo caso, al plantear la relación entre imperio y lengua, Nebrija más bien estaba remedando a su maestro Lorenzo Valla, que en sus Elegantiae linguae latinae (1471) recordaba a todo el mundo cómo Italia gobernaba el mundo moderno a través de su lengua, aunque ya no dominara realmente a otros pueblos, como en tiempos romanos, ahora sucedía todo lo contrario: eran las tropas españolas y francesas las que ocupaban el territorio italiano, y él estaba al servicio del virrey español de Nápoles (entre 1437-1448 llegó a ser secretario personal de Alfonso V de Aragón). A ese respecto, para mostrar la poca popularidad de la gramática castellana de Nebrija (1492), basta recordar que no hubo una segunda edición hasta siglos después, al contrario que de la latina (su obra más estimada), y que en todo caso los misioneros españoles no obedecieron las órdenes reales de enseñar el catecismo en castellano, sino que elaboraron nuevas gramáticas de cada país (Asensio 1960). ${ }^{9}$

Pues bien, cuando los misioneros católicos quisieron hacer unas gramáticas con las lenguas del Nuevo Mundo, tuvieron el mismo proceso «mediato» que Nebrija (de usar una gramática ajena pasada para construir otra ajena presente) y por ello se hizo tan popular entre ellos su gramática latina, no la castellana. Creo que esta conexión particular entre el latín y las lenguas americanas no se ha observado y reconocido hasta tiempos recientes (hasta los varios congresos del 92 en homenaje a Nebrija), pues el profesor Antonio Quilis (editor ilustre y reiterado de la gramática castellana de Nebrija) creyó al principio que era esta gramática el modelo usado. He tenido alguna discrepancia reciente con colegas hispanistas (especialistas en literatura contemporánea) que tomaban el latinismo humanista como prueba de etnocentrismo, dado que el castellano era finalmente un derivado del latín: sin advertir que ese modo de

9 Ver también Del Pino (2010). 
concebir la lengua propia como latina era más bien medieval, y que lo que caracterizaba al Renacimiento era un nuevo latinismo clásico, más sujeto al modelo ciceroniano, que partía precisamente de la distancia advertida con el mediocre latinismo escolástico, infectado de palabras y expresiones vernaculares.

No es casual que fuera un latinista renovador como Nebrija (precedido de sus maestros italianos) quien iniciara paradójicamente esta labor vernacularizante. No es casual tampoco que no hubiera gramáticas vernaculares hasta que se impuso el nuevo modelo latino, como patrón general digno de seguirse de ejemplo. Los autores de nuevas gramáticas indígenas necesitaron primeramente apreciar el ejemplo latino para construir un modelo adecuado a las nuevas lenguas: lo que quiere decir que (independientemente de sus iniciales desviaciones latinistas en la elaboración de nuevas gramáticas americanas, efecto natural del empleo de un modelo previo) no habrían podido hacerse esas gramáticas sin contar con la ayuda latina. Así lo creyó el doctor Rowe (1974) en un ensayo especial dedicado a estas gramáticas:

La tendencia latinizante era muy fuerte, pero no debería exagerarse. Nebrija, en su gramática española de 1492, hizo un intento de describir, al menos, algunos de los rasgos de la lengua española en sus propios términos (...). Un gramático actual que intente usar estas obras tempranas descubre que puede, en general, reinterpretar casi correctamente el material vernacular presentado en este marco latino; si bien puede bloquearse ante el tratamiento tan deficiente dado a la fonología, y por el hecho de que no se recogen algunas formas y construcciones ajenas al latín. ${ }^{10}$

Lo mismo ocurrió con las descripciones etnográficas de los humanistas, donde el concepto de civilización se refería inicialmente a caracteres particulares como la escritura. Me gustaría poder mostrar

10 Rowe (1974: 365). La traducción es del autor del presente trabajo. 
que, al igual que los latinismos de las gramáticas andinas tempranas (como la de Domingo de Santo Tomás de 1560, por ejemplo) no fueron un impedimento del posterior conocimiento del quechua y que las otras gramáticas jesuitas (en especial la de Diego González Holguín) fueron posteriormente reconociendo poco a poco los caracteres propios y no latinos; ocurrió lo mismo en las descripciones etnográficas: se apoyaron inicialmente en una muletilla romanista, que ejerció el papel de patrón comparativo para poder dibujar los nuevos renglones culturales de otro pueblo desconocido, pero lograron finalmente lograr una descripción propia. Es decir, que se trató de un proceso cuyo etnocentrismo inicial fue de grado y no de género, de algo que podía irse removiendo gradualmente (como una muletilla, molde o armazón provisional), a medida que el conocimiento empírico avanzase.

\section{El caso del jesuita Acosta y la distinción cultural estable- CIDA POR LA ESCRITURA}

En ese sentido gradual respecto de la distinción de las diferencias culturales, que permite posteriormente su equiparación digna, es como creo que puede considerarse la exigencia inicial del jesuita José de Acosta en favor de una escritura fonética, como la única digna de llamarse escritura; así cabe interpretar mejor el hecho mismo de ser ese rasgo escrito un criterio válido de progreso cultural. Al frente de su tratado misional de 1589 figura un proemio poniendo su énfasis en señalar que había varios tipos de pueblos y que -consecuentemente- no puede ser igual el método evangélico idóneo para cada uno. Ahí es donde tenemos un primer indicio de su valoración de los libros y la escritura como criterio cultural clasificatorio: 
Siendo, pues, muchas las provincias, naciones y categorías [cualidades, apud Mateos] de estas gentes, sin embargo me ha parecido después de larga y diligente consideración que pueden reducirse a tres clases o categorías [de bárbaros...] La primera es la de aquellos que no se apartan demasiado de la recta razón [...] y a ella pertenecen los que tienen república estable, leyes públicas, ciudades fortificadas, magistrados obedecidos, seguro y próspero comercio [suprimido en Mateos] y, lo que más importa, uso y conocimiento de las letras, porque dondequiera que hay libros y monumentos escritos, la gente es más bumana y política. ${ }^{11}$

Cuando publicó después su Historia natural y moral de las Indias, volvió a dedicar una cierta atención prioritaria al asunto de la escritura. Debe aclararse de entrada que el jesuita en esta obra centra su atención sobre los pueblos que pueden considerarse culturalmente más avanzados (los mexicas y los incas, como recoge asimismo de las Indias orientales solamente el caso de los chinos y japoneses, que describe con detalle en varios capítulos tanto de cultura religiosa como secular: especialmente por su escritura). Cuando se ocupa de ellos, especialmente en los libros de historia moral (V-VII), enumera una serie de instituciones representativas que va describiendo cada una en sucesivos capítulos, donde la escritura está considerada en segundo lugar: inmediatamente después de los calendarios y cómputo del tiempo, pero antes de otras «instituciones» contempladas en el libro VI (gobierno, edificios, tributos, oficios, correos, leyes, modos de guerrear, educación de la juventud y bailes).

Dedica seis capítulos solamente (de un total de 28 que tiene el libro VI, el libro que se ocupa de las instituciones no religiosas) al tema de la escritura. En esos seis capítulos dedicados a la escritura, se ocupa también de otros pueblos civilizados (aunque todos indianos, como son mexicanos, chinos y japoneses), y solamente el capítulo 8 se centra en la escritura peruana. Debemos reconocer

11 Acosta (1954: 392). Sigo la versión de F. Mateos de las Obras del P. José de Acosta (1954). Cursivas y correcciones entre corchetes, mías. 
que el jesuita habla, con conocimiento de causa, tanto de la escritura mexicana en jeroglifos como de la china y japonesa. Tiene información más o menos directa de todas, pues le hablaron extensamente de ellas dos jesuitas bien informados, como eran Juan de Tovar para la escritura mexicana (profesor del colegio de Tepotzotlán, donde los jesuitas tenían un centro especial para hijos de nobles mexicanos), que reúne para Acosta un códice traducido del nahuatl (Lafaye 1972), que aún se conserva en Estados Unidos (el Códice Tovar, en la Biblioteca John Carter Brown); y para la china Alonso Sánchez (que venía a ver al rey, en un viaje expreso desde China y que viaja con él desde México a España). De la japonesa parece haber visto Acosta huellas en la biblioteca de El Escorial.

Su información ajena era de primera mano, como se ve, pero también tenía conocimiento directo del tema, tanto de la escritura china como de la mexicana: pasó nueve meses en México recorriendo el país y reuniendo información para su obra histórica. Justamente, cuando desembarcó en junio de 1586 en la costa occidental de México (Guatulco), se encontró con varios comerciantes chinos, y se atrevió a hacer el experimento de hacerle escribir a uno una frase («José de Acosta ha venido del Perú») y a otro leerla, para averiguar si la escritura china permitía recoger literalmente las palabras pronunciadas. El asunto le continuaba interesando particularmente cuando recibió luego el códice mexicano de Tovar, pues se conserva la carta que escribió al padre Juan de Tovar, que explica su personal relevancia literal para creer luego la historia propia que narran los nativos:

Holgado he de ver y pasar la Historia Mexicana que V. R. (vuestra reverencia) escribió, y pienso holgarán también en Europa con ella por la curiosidad que tiene cerca del gobierno y sucesión y ceremonias de los indios mexicanos. Mas deseo me satisfaga V. R. a algunas dudas que se me han ofrecido. La $1^{\text {a }}$ es qué certidumbre y autoridad tiene esta relación o historia. La $2^{\mathrm{a}}$, cómo pudieron los indios sin escritura (pues no la usaron) conservar por tanto tiempo la memoria de tantas y tan varias cosas. Lo tercero, cómo se puede creer que las oraciones o arengas que 
se refieren en esta historia las hayan hecho los antiguos retóricos que en ella se refieren, pues sin letras no parece posible conservarse oraciones largas, y en su género elegantes. A estas dudas me satisfaga V. R. para que el gusto de esta historia no se deshaga con la sospecha de no ser tan verdadera que se deba tener por historia. ${ }^{12}$

La respuesta que le diera el padre Tovar la recoge de algún modo el propio Acosta en el capítulo siete de este libro VI, para tranquilidad del lector:

Pero, porque sus figuras y caracteres no eran tan suficientes como nuestra escritura y letras, por eso no podían concordar tan puntualmente en las palabras sino solamente en lo sustancial de los conceptos. Mas, porque también usan referir de coro arengas y parlamentos que hacían los oradores y retóricos antiguos, y muchos cantares que componían sus poetas -lo cual era imposible aprenderse por aquellos hieroglíficos y caracteres-, es de saber que tenían los mexicanos grande curiosidad en que los muchachos tomasen de memoria los dichos parlamentos y composiciones. Y para esto tenían escuelas y como colegios o seminarios adonde los ancianos enseñaban a los mozos éstas y muchas otras cosas que, por tradición, se conservan tan enteras como si hubiera escritura dellas: especialmente las oraciones famosas hacían -a los muchachos que se imponían para ser retóricos y usar oficio de oradores- que las tomasen palabra por palabra. Y muchas de éstas, cuando vinieron los españoles y les enseñaron a escrebir y leer nuestra letra, los mismos indios las escribieron, como lo testifican hombres graves que las leyeron. Y esto se dice porque, quien en la historia mexicana leyere semejantes razonamientos largos y elegantes, creerá fácilmente que son inventados de los españoles, y no realmente referidos de los indios; mas, entendida la verdad, no dejará de dar el crédito que es razón a sus historias. ${ }^{13}$

A pesar de la ayuda nemotécnica recibida por parte de estos jóvenes relatores, como le explicaba el padre Tovar, su pintura mexica-

12 Citado en Rodríguez Carracido (1899: 97).

13 Acosta (2008: 209). 
na en jeroglifos tampoco adquiría la calidad de «escritura fonética», como el autor quiere dejar sentado en un inicial capítulo 4: «Que ninguna nación de indios se ha descubierto que use de letras», antes de tratar de la escritura mexicana y de la china. El autor propone denominar pintura (y no escritura) a este sistema particular de conservar la memoria, siguiendo directamente el criterio aristotélico. Efectivamente, en este caso citará la obra directamente del griego (Peri Hermeneias), traducido más tarde en latín como De interpretatione (lo que hizo dudar a todos a qué obra se refería con su abreviación «Perihen», hasta que la helenista Elvira Gangutia lo descifró recientemente). Casi al inicio de esta obra Peri Hermeneias, Aristóteles intentaba definir la relación entre sonido, escritura y significación: «Así, pues, lo <que hay $>$ en el sonido son símbolos de las afecciones $<$ que hay $>$ en el alma, y la escritura $<$ es símbolo $>$ de lo $<$ que hay $>$ en el sonido. Y, así como las letras no son las mismas para todos, tampoco los sonidos son los mismos» (Aristóteles 1995: 35-46).

Conviene explicar detenidamente que esta tipificación literaria no significaba para el jesuita una carencia general: solamente era una manera especifica de conservar sus antigüedades. Lo que Acosta (Lib. VI, cap. 4). elabora entonces teóricamente sirve para sus propios fines, para dar cuenta de la diferencia de medios de conservar la memoria, del siguiente modo (señalo en cursivas):

Las letras se inventaron para referir y significar inmediatamente las palabras que pronunciamos, así como las mismas palabras y vocablos -según el Filósofo (Aristóteles: Periber, cap. 1)- son señales inmediatamente de los conceptos y pensamientos de los hombres. Y lo uno y lo otro (digo las letras y las voces) se ordenaron para dar a entender las cosas: las voces a los presentes, las letras a los ausentes y futuros. Las señales que no se ordenan de próximo a significar palabras, sino cosas, no se llaman ni son en realidad de verdad letras, aunque estén escritas: así como una imagen del sol pintada no se puede decir que es escritura o letras del sol sino pintura [...] Estas tales señales no se dicen -ni son propiamente- letras ni escritura, sino cifras o memoriales, como las que 
usan los esferistas o astrólogos para denotar diversos signos o planetas de Marte, de Venus, de Júpiter, etc. [...] De manera que escritura y letra solamente las usan los que con ellas significan vocablos; $\mathrm{y}$, si inmediatamente significan las mismas cosas, no son ya letras ni escritura sino pintura y cifras. ${ }^{14}$

Queremos insistir que la disponibilidad a partir de la mera pintura no significa para Acosta la imposibilidad de conservar memoria del propio pasado por mucho tiempo (que en el caso incaico llega a los 400 años y en el mexicano a los 800). Quiero notar de pasada que el Inca Garcilaso creyó este cálculo acostiano sobre la memoria histórica incaica, antes que otro superior en años, propuesto por el padre Valera. ${ }^{15}$ Acosta se apresura, al señalar que las sociedades indianas de América y Asia no tienen escritura sino pintura, a dejar claro que no se trata de diferencias de memoria sino de soporte de la memoria:

De aquí se sacan dos cosas bien notables: la una es que la memoria de historias y antigüedad puede permanecer en los hombres por una de tres maneras: [a] o por letras y escritura, como lo usan los latinos y griegos y hebreos, y otras muchas naciones; [b] o por pintura, como casi en todo el mundo se ha usado [...] [c] o por cifras o caracteres, como el guarismo significa los números de ciento, de mil y los demás, sin significar esta palabra ciento ni la otra mil. El otro notable que se infiere es el que en este capítulo se ha propuesto, es a saber: que ninguna nación de indios que se ha descubierto en nuestros tiempos usa de letras ni de escritura sino de las otras dos maneras, que son imágines o figuras; y entiendo esto no sólo de los indios del Perú y de los de Nueva España, sino en parte también de los japones y chinas. ${ }^{16}$

Yo no creo que pueda inferirse de aquí ninguna inferioridad esencial y sistemática de uno u otro sistema de memoria, pues el au-

14 Acosta (2008: 205).

15 Insiste: «los Incas reyes del Perú, que reinaron por espacio de más de 400 años, aunque el P. Blas Valera dice que fueron más de 500 y cerca de 600» (Comentarios reales, II, 1).

16 Acosta (2008: 206). 
tor lo deja bien claro en la taxonomía triple que ofrece. Pero además lo afirma taxativamente, al concluir su apartado sobre la escritura de este libro en el capítulo 9 (titulado Del orden que guardan en sus escrituras los indios), tras tratar de cada sistema conocido de escritura, concluye que todos son igualmente ingeniosos:

Los latinos y griegos escribieron de la parte izquierda a la derecha, que es el común y vulgar modo que usamos. Los hebreos, al contrario, de la derecha comienzan hacia la izquierda, y así sus libros tienen el principio donde los nuestros acaban. Los chinos no escriben ni como los griegos ni como los hebreos, sino de alto abajo, porque como no son letras sino dicciones enteras -que cada una figura o carácter significa una cosa- no tienen necesidad de trabar unas partes con otras, y así pueden escrebir de arriba abajo. Los de México, por la misma razón, no escrebían en renglón de un lado a otro sino al revés de los chinos: comenzando de abajo iban subiendo, y de esta suerte iban en la cuenta de los días y de lo demás que notaban [...] Finalmente, todas cuatro diferencias se hallan en escrituras: unos escriben de la derecha a la izquierda, otros de la izquierda a la derecha, otros de arriba abajo, otros de abajo arriba; que tal es la diversidad de los ingenios de los hombres. ${ }^{17}$

Un antropólogo, si quisiera subrayar el derecho a la diferencia de escrituras en igualdad de condiciones para cada cultura, no lo expresaría seguramente de una manera mejor. Y lo mismo va a ocurrir cuando se ocupe del Perú: como veremos, dedica a los sistemas peruanos de conservar su memoria el capítulo 8 (el más largo de todos, tras hablar de China, Japón y México: De los memoriales y cuentas que usaron los indios del Pirû), donde reconoce que los peruanos no tienen ningún sistema de escritura, aunque saben conservar memoria de sus tradiciones y de sus asuntos importantes por otros medios materiales impensados (de lana, de maíz o de piedra) que vuelven a demostrar el ingenio igual -si no superior-al de los cristianos europeos. Dejémosle la palabra:

17 Acosta (2008: 211). 
Los indios del Perú, antes de venir españoles, ningún género de escritura tuvieron, ni por letras ni por caracteres o cifras o figurillas, como los de la China y los de México; mas no por eso conservaron menos la memoria de sus antiguallas, ni tuvieron menos su cuenta para todos los negocios de paz y guerra y gobierno. Porque en la tradición de unos a otros fueron muy diligentes, y como cosa sagrada recibían y guardaban los mozos lo que sus mayores les referían, y con el mismo cuidado lo enseñaban a sus sucesores. Fuera desta diligencia, suplían la falta de escritura y letras parte con pinturas como los de México -aunque las del Perú eran muy groseras y toscas-, parte y lo más con quipos. Son quipos unos memoriales o registros hechos de ramales, en que diversos ñudos y diversos colores significan diversas cosas. ${ }^{18}$

A continuación, sin asomar el más leve signo de inferioridad, más bien al contrario, se ocupa del quipu:

Es increíble lo que en este modo alcanzaron, porque cuanto los libros pueden decir de historias y leyes y ceremonias y cuentas de negocios todo eso suplen los quipos tan puntualmente que admira. Había, para tener estos quipos o memoriales oficiales diputados -que llaman hoy día quipocamayo-, los cuales eran obligados a dar cuenta de cada cosa como los escribanos públicos acá, y así se les había de dar entero crédito. Porque para diversos géneros -como de guerra, de gobierno, de tributos, de ceremonias, de tierras- había diversos quipos o ramales; y en cada manojo déstos tantos ñudos y ñudicos e hilillos atados -unos colorados, otros verdes, otros azules, otros blancos- y finalmente tantas diferencias que, así como nosotros de veinte y cuatro letras -guisándolas ${ }^{19}$ en diferentes maneras- sacamos tanta infinidad de vocablos, así éstos de sus ñudos y colores sacaban innumerables significaciones de cosas. Es esto de manera que

18 Acosta (2008: 209-210).

19 Merece la pena observar este calificativo metafórico familiar, de «guisar», por «combinar» cada uno a su manera los mismos condimentos. El autor era muy aficionado a la mesa, y sus conocidos le describirán en su vejez como un hombre obeso. 
hoy día acaece en el Perú, a cabo de dos y tres años cuando van a tomar residencia a un corregidor, salir los indios con sus cuentas menudas y averiguadas pidiendo que en tal pueblo le dieron seis huevos y no los pagó, y en tal casa una gallina y acullá dos haces de hierba para sus caballos, y no pagó sino tantos tomines ${ }^{20} \mathrm{y}$ queda debiendo tantos: y para todo esto [dejan] hecha la averiguación allí al pie de la obra, con cantidad de ñudos y manojos de cuerdas que dan por testigos y escritura cierta. ${ }^{21}$

Finalmente se ocupa de otros sistemas mnemotécnicos incaicos, con el mismo fin de dejar constancia de su particular 'ingenio' cultural, que compara entre sí:

Pues verles otra suerte de quipos que usan, de granos de maíz, es cosa que encanta. Porque una cuenta muy embarazosa -en que tendrá un muy buen contador que hacer por pluma y tintapara ver a cómo les cabe entre tantos tanto de contribución, sacando tanto de acullá y añadiendo tanto de acá con otras cien retartalillas, ${ }^{22}$ tomarán estos indios sus granos y pornán uno aquí, tres acullá, ocho no se dónde; pasarán un grano de aquí, trocarán tres de acullá y, en efecto, ellos salen con su cuenta hecha puntualísimamente sin errar una tilde. Y mucho mejor se saben ellos poner en cuenta y razón de lo que cabe a cada uno de pagar, o dar, que sabremos nosotros dárselo por pluma y tinta averiguado. Si esto no es ingenio y si estos hombres son bestias, júzguelo quien quisiere, que lo que yo juzgo de cierto es que en aquello a que se aplican nos hacen grandes ventajas. ${ }^{23}$

Quiero detenerme en esta frase: «nos hacen grandes ventajas», porque recuerda mucho la frase «nos hacen mucha ventaja» que el profesor Murra (2002) recogió como excepcional de parte de algunos observadores tempranos (como Gaspar de Espinosa, Cieza de León, Polo de Ondegardo o Domingo de Santo Tomás). De hecho,

20 Moneda de plata que se usaba en algunas partes de América.

21 Acosta (2008: 210).

22 Retahíla de palabras, palabrería.

23 Acosta (2008: 211). 
se le volverá a oír al mismo Acosta cuando responde afirmativamente a los mestizos de Lima que le entrevistan en 1583, durante el tercer concilio limense, buscando opiniones favorables a la ordenación de sacerdotes, suspendida desde 1578 por el rey. El estado de opinión de estos mestizos aspirantes a sacerdotes en esa fecha coincide con el de Acosta, cuando describen a las autoridades española su autoestima como grupo: «en aquello en que ponen la mano ninguna nación les hace ventaja en razón y entendimiento, ánimo y esfuerzo, destreza de armas y de caballos y otros ejercicios virtuosos». ${ }^{24}$

\section{La huella de Acosta entre los nativos peruanos}

Como se verá enseguida, el mestizo peruano que más buena nota toma de estas propuestas es el Inca Garcilaso, con toda seguridad bien informado de la buena inclinación del jesuita Acosta hacia la nueva aprobación real del sacerdocio de mestizos durante ese concilio: justo la profesión que ha decidido tomar, si el rey lo autoriza, como ocurre en 1588 durante las gestiones en Roma del padre Acosta a favor de la aprobación del concilio limeño, cuyas actas redactó y portó personalmente.

Quiero reiterar que este capítulo de la historia indiana de Acosta, de tono claramente reivindicativo, llamó particularmente la atención del Inca Garcilaso, que lo recoge como referencia en el capítulo 13 del libro II de la segunda parte de los Comentarios Reales: «El cual [contador] tomando sus memoriales, que eran los nudos, señales y cifras leía por ellas sus historias mejor y más apriesa que un español por su libro, como dice el padre Acosta, libro VI, capitulo $8 »$. Aunque algunos garcilasistas han dudado de esta confianza plena del Inca Garcilaso en las descripciones y apología incaicas de Acosta, es obligado reconocer que recurre en varias ocasiones a

24 Olaechea (1992: 173). 
estos capítulos del libro VI de Acosta. En particular me fijaré en la defensa que hace de la inteligencia indiana, al comienzo del libro VI, dedicada a su cultura no religiosa, pero esta vez tomaré la cita acostiana del propio Garcilaso:

Y el Padre Maestro Acosta, Libro VI, capítulo 1, dice lo que se sigue en favor de los incas y de los mexicanos: «Habiendo tratado lo que toca a la religión que usaban los indios, pretendo en este libro escribir sus costumbres y policía y gobierno para [...] deshacer la falsa opinión que comúnmente se tiene de ellos como de gente bruta y bestial y sin entendimiento, o tan corto que apenas merece ese nombre; del cual engaño se sigue hacerles muchos y muy notables agravios [...] Esta tan perjudicial opinión no veo medio con que pueda mejor deshacerse que con dar a entender el orden y modo de proceder que éstos tenían cuando vivían en su ley, en la cual, aunque tenían muchas cosas de bárbaros y sin fundamento, pero había también otras muchas dignas de admiración, por las cuales se deja bien entender que tienen natural capacidad para ser bien enseñados, y aun en gran parte hacen ventaja a muchas de nuestras repúblicas [...]». Hasta aquí es del Padre Maestro Josef de Acosta, cuya autoridad, pues es tan grande, valdrá para todo... ${ }^{25}$

No era la primera vez que el Inca asumía como propia esta defensa explícita del ingenio americano y no solamente en esta obra. Es también, curiosamente, en el mismo libro y capítulo de su obra anterior (La Florida del Inca, libro II, cap. 27), donde hace alusión a esta misma frase del padre Acosta, para defender que son reales los discursos elegantes que acaba de recoger de los nativos de la Florida. Exactamente con la misma inquietud que preocupaba al jesuita Acosta, que no se le creyera en Europa cuando reproduce la retórica mexicana del códice Tovar:

Donde [se] responde a una objeción. Antes que passe adelante en nuestra historia, será bien responder a una objeción que se nos

25 (Comentarios Reales, Libro II, cap. 27). 
podría poner, diciendo que en otras historias de las Indias Occidentales no se halla[n] cosas hechas ni dichas por los indios como aquí las escribimos: porque comúnmente son tenidos por gente simple sin razón ni entendimiento, y que en paz y en guerra se han [es decir, comportan] poco más que bestias, y que conforme a esto no pudieron hacer ni decir cosas dignas de memoria y encarecimiento, como algunas que hasta aquí parece que se han dicho, y adelante con el favor del cielo diremos; y que lo hacemos, o por presumir de componer o por loar nuestra nación, que, aunque las regiones y tierras estén tan distantes, parece que todas son Indias. A esto se responde primeramente, que la opinión que de los indios se tiene es incierta, y en todo contraria a la que se debe tener, como lo nota, arguye y prueba muy bien el muy venerable padre Joseph de Acosta en el primer capítulo del sexto lib. de la Historia natural y moral del nuevo orbe, donde remito al que lo quisiere ver: donde sin esto, hallará cosas admirables escritas como de tan insigne maestro. ${ }^{26}$

La confianza total que deposita Garcilaso en la autoridad de Acosta le lleva a preferirla a la de sus propios compañeros de infancia, a quien había pedido inútilmente que le midiesen las dimensiones exactas de la fortaleza de Sacsahuaman:

siendo ellas tan grandes que espantan, como lo dice el muy reverendo padre Josef de Acosta hablando de esta misma fortaleza [Sacsahuamán]. Que yo, por tener la precisa medida del grandor de muchas de ellas, me quiero valer de la autoridad de este gran varón: que, aunque la he pedido a los condiscípulos y me la han enviado, no ha sido la relación tan clara y distinta como yo la pedía... ${ }^{27}$

El inca había recurrido al jesuita en realidad para tener una medición precisa, por no tenerla él de otro modo, en realidad. Es curioso que el editor canónico del Inca Garcilaso ${ }^{28}$ haya retocado el

\footnotetext{
26 (La Florida del Inca, Libro II, cap. 27).

27 (Comentarios Reales Libro VII, cap. 27).

28 Angel Rosenblat, seguido en ello por otros editores peruanos, como Miró Quesada; no así por Carlos Araníbar (tomo II, p. 481), que moderniza para recupe-
} 
texto original de Lisboa, corrigiendo la frase afirmativa del Inca con una partícula negativa, que no existe en el original: «que yo, por [no] tener la precisa medida» de la fortaleza. Es quizá algo contradictoria la falta de confianza que tienen los editores actuales, y no precisamente los peores, en la escala de valores del autor que editan. Durante el año 2009, en que se celebraron numerosos homenajes a la obra paradigmática del Inca Garcilaso, tuve ocasión de participar en seis de ellos (Boston, Lima, Madrid, Sevilla, Cusco y Córdoba), y me vi obligado a sostener la fiabilidad del ilustre mestizo en sus continuas referencias elogiosas hacia el jesuita Acosta. Porque para unos no son de fiar algunas, simplemente, por la imprecisión de las mismas, suponiendo que las muda a capricho, o incluso se equivoca en las referencias; para otros se equivoca ingenuamente al creer en el indigenismo del jesuita, a pesar de los numerosos testimonios a favor de estos que dejó Acosta a lo largo de su vida. Para otros, finalmente, incluso no es sincero el propio testimonio acostiano del inca $y$, al alabarlo, se supone que es porque debe disimular su opinión para evitar el control de un hombre poderoso.

Debo confesar que todo este conjunto de sospechas choca de pleno, frontalmente, contra numerosas referencias precisas del Inca Garcilaso, de las cuales he procurado ofrecer aquí una muestra pequeña. La edición del profesor Carlos Araníbar en 1991, a pesar de sus comentadas licencias editoriales formales, nos permite tener constancia de la estrecha conexión que le une a ambos autores gracias a sus cuidadosos sangrados de citas y su abultado volumen de notas finales, con más de doscientas páginas. Yo, por mi parte, no creo que pudiera pensarse siquiera en equivocaciones de cita, dado que el Inca depositaba su autoridad en una obra que se había

rar el sentido genuino del texto: «Que yo para tener la precisa medida...». Una edición no es más crítica por ser paleográfica, sino por captar mejor la intención del autor. En este caso, la partícula alterada 'para' de Araníbar comprende mejor al autor, pero el 'no' añadido de Rosenblatt lo traiciona. 
publicado recientemente, y con varias reediciones (castellanas en 1590, 1591, 1608, y europeas: de 1596 en italiano, 1598 en francés, alemán y flamenco y 1601 en latín), en cuyo cotejo podría el lector cuidadoso detectar estas faltas. ¿No temía que sus lectores perdiesen su propia confianza por causa de sus citas descuidadas? No puedo creer tampoco en falta alguna de información del ilustre mestizo sobre sus aliados jesuitas, dado que el Inca debía al padre Acosta precisamente un hecho sustancial de su propia vida: la defensa de la ordenación sacerdotal de los mestizos, autorizada en 1588 por Felipe II a instancias suyas y del tercer concilio limense (Del Pino 2010a y 2010b). Por último, no creo que pudiera pensarse que hubiese ningún temor de parte del ilustre vecino de Córdoba hacia el poder censor del jesuita Acosta (motivando su disimulo en contradecirle personalmente), ya que Acosta acababa de verse desautorizado por su superior Acquaviva en 1593, en medio de una congregación general donde se había decidido la prohibición de ingreso a la Compañía de Jesús de nuevos conversos, hijos de judíos o moriscos. Garcilaso no podía ignorar esto en una Andalucía llena de jesuitas hijos de conversos, que acogieron a Blas Valera con tanto afecto (Medina Rojas 1999), y cuya persecución de parte de los cristianos viejos debiera recordarle obsesivamente la suerte indecisa de los mestizos en las Indias.

No puedo entender las recientes reticencias del garcilasismo hacia la obra del padre Acosta y, menos aún su coincidencia con las posiciones postcoloniales que ha decidido declararle la guerra al humanismo letrado. Considerar que este jesuita, de familia conversa y siempre en defensa de la dignidad cultural americana, es en realidad un representante del poder colonial, roza la «impostura» (la confusión de autor), por no decir incluso la obsesión. Esta guerra contra el humanismo letrado podría afectar de pleno a la obra del Inca Garcilaso. Se han producido extrañas y recientes conexiones entre esta escuela postcolonialista (más bien sociológica que histórico-literaria), que ha decidido prescindir de los textos a favor del 
contexto político - por un lado-, y el grupo de historiadores italianos que ha decidido, por el contrario, construir nuevos manuscritos para probar que la obra del indio Guamán Poma de Ayala (no la del inca Garcilaso) es el verdadero legado del padre Blas Valera: un hombre culto y mestizo que -al parecer- sí les merece respeto como autor. Para este grupo, Garcilaso no interpreta bien al padre Valera, a pesar de habérselo apropiado ¿Cabe, por otro lado, mayor atentado contra un autor como Guamán Poma (a quien se supone simplemente hombre de paja que firma una obra ajena), teniendo en cuenta que llena de tachaduras su obra propia, que colabora con los mismos dibujos en la obra del poderoso mercedario Murúa (de quien se separa indignado como autor), y que se dibuja a sí mismo varias veces como autor? Es raro, por último, que no se haya denunciado suficientemente por los expertos concernidos en la materia (no me refiero obviamente a los estudiosos de Guamán Poma, que ya lo han hecho) el empeño de Laura Laurencich y su grupo italiano en mostrar que el quipu es un alfabeto (y no solo un instrumento de la memoria), solo porque (según ellos) se ha conservado un manuscrito del padre Valera que lo avala.

Creo que, puestos a elaborar un contexto político creíble que afecte a las contradicciones entre los actores implicados en el constructo colonial (peninsulares, criollos, mestizos e indios americanos), deberíamos estar precavidos contra simplificaciones burdas, tales como creer de común acuerdo los intereses de todos los miembros de cada grupo implicado. Es evidente que los jesuitas no tenían el mismo interés que otros círculos peninsulares de poder colonial y, sobre todo, que no todos los jesuitas pensaban de la misma manera. Igualmente es evidente que los jesuitas españoles apostaron mucho tiempo por empresas criollas. Y, viceversa, también ocurrió lo contrario, si hacemos caso de los numerosos testimonios indigenistas de que disponemos a favor de los jesuitas (de parte del Inca y de Guamán Poma). 
Al final, una persona como Acosta no solamente defendió el valor de la escritura, sino que dejó una buena porción de escritos referidos al Perú. Su tratado misional y su historia indiana han puesto al Perú en conocimiento de todo el mundo, y varias de las discusiones sobre la física y las sociedades del globo (el soroche, la corriente de Humboldt, el concepto de behetría y sociedad natural -en Locke, por ejemplo- ${ }^{29}$ o las conjeturas evolucionistas de Morgan) le deben a él precisamente su conciencia primera. Pero, sobre todo, se deben a él las primeras ediciones de libros publicados en Sudamérica (1584-1586), que llevan su firma y se imprimieron bajo su asesoría.

Como dedicó muchas horas a impartir diversas noticias de historia natural y moral (previamente a su publicidad en 1588 y 1590) en el colegio de San Pablo, sede de la antigua Biblioteca Nacional del Perú, me pareció que estaba justificado dedicarle buena parte de este ensayo. No solamente sus colecciones de libros, tan celosamente guardadas y recuperadas por la actual dirección de la misma, sino el propio edificio de esa biblioteca y su significado como centro peruano de saber, merece figurar como parte integral de su propia memoria histórica este personaje excepcional del periodo colonial, perteneciente a su etapa fundacional.

29 Sobre el uso por parte de Locke de cronistas de Indias como Acosta, ver Batz (1974). Sabine MacCormack dedicó varios ensayos a la figura intelectual del P. Acosta, especialmente en sus últimos años, como podrá verse en su bibliografía. Pero también en otros escritos sobre problemas socio-económicos que no son de historia intelectual, señaló la conciencia ética despierta del jesuita, que defendió a los indios de Potosí, incluso en el caso de que hurtasen a los empresarios mineros españoles (porque también los cristianos les hurtaban su recursos naturales): «porque no solo se ha de mantener y vestir, que a un esclavo debemos esto, sino enriquecerse y aprovecharse, como hacemos nosotros en su tierra» (MacCormack 2002: 84). 


\section{REFERENCIAS}

Acosta, José de

1954 Obras del P. José de Acosta. Biblioteca de Autores Españoles. Madrid: Atlas.

2008 Historia natural y moral de la Indias. Edición crítica de Fermín del Pino. Colección de acá y de allá. Fuentes etnográficas, n. 2. Madrid: C.S.I.C.

\section{ARISTÓTELES}

1995 «Sobre la interpretación». En Tratados de lógica (Organon) II. Traducción de Miguel Candel San Martín. Madrid: Gredos, pp. 35-81.

Asensio, Eugenio

1953 «Dos cartas desconocidas del Inca Garcilaso». Nueva Revista de Filología Hispánica, n. VII, pp. 583-593.

1960 «La lengua compañera del imperio (a). Historia de una idea de Nebrija en España y Portugal». Revista de Filología Española, vol. XLIII, n. 3-4, pp. 399-413.

Avilés Fernández, Miguel (ed.)

1976 Sinapia: una utopía española del Siglo de las Luces. Madrid: Editora Nacional.

BATz, William G.

1974 «The Historical Anthropology of John Locke». Journal of the History of Ideas, vol. 35, n. 4, octubre-diciembre, pp. 663-670.

Bernand, Carmen

2011 «Hebreos, romanos, moros e Incas: Garcilaso de la Vega y la arqueología andaluza». Nuevo Mundo Mundos Nuevos [En línea], https://journals.openedition.org/nuevomundo/60885. Consultado en julio de 2017.

Del Pino, Fermín

1976 «Canarias y América en la historia de la Etnología primigenia: usando una hipótesis». Revista de Indias, vol. XXXVI, n. 145-146, pp. $99-156$. 
2002 «Procedencia clasicista de los colectores de refranes castellanos». Revista de Dialectología y Tradiciones Populares, vol. LVII, n. 2, pp. 203-224.

2010a «Mestizos americanos y conversos hispanos ¿posibles aliados?». En: Carmen de Mora, Guillermo Serés y Mercedes Serna (eds.). Humanismo, mestizaje y escritura en los Comentarios reales. Madrid: Iberoamericana, pp. 275-293.

2010b «¿Dignidad cultural o protoidentidad cristiana de lo inca? Acerca del sentido preferente de los comentarios garcilasianos al padre Acosta». En: José A. Mazzotti (ed.). Renacimiento mestizo: los 400 años de los Comentarios reales. Madrid: Iberoamericana, pp. 51-77.

2010c «La lengua castellana como eje de la identidad latinoamericana a partir de la Independencia». Biblioteca Virtual Cervantes. Consultado en julio de 2017.

$<$ http://www.cervantes.es/imagenes/image/lengua/bicentenario_independencias/del_pino_ponencia.pdf $>$

Díez del Corral, Luis

1957 La función del mito clásico en la literatura contemporánea. Madrid: Gredos.

GRUZINSKI, Serge

2001 «Les mondes melés de la monarchie catholique et autres 'connected histories'». Annales Histoire, Sciences Sociales, 56e année, 1, pp. 85-117.

2004 Les quatre parties du monde. Histoire d'une mondialisation. París: Éditions de La Martinière.

2006 «Mundialización, globalización y mestizajes en la Monarquía católica». En: Antonio Feros Carrasco y Roger Chartier (coords.). Europa, América y el mundo: tiempos históricos. Madrid: Marcial Pons, pp. 217-237.

LAFAYE, Jacques

1972 Manuscrit Tovar: origines et croyances des Indiens du Mexique: Relación del origen de los Yndios, que havitan en esta Nueva España segun sus historia; tratado de los ritos y ceremonias y dioses que en su gentilidad usavan los Indios de esta Nueva España. Édition établie d'après le manuscrit de la John Carter Brown Library. Graz, Austria: Akademische Druck u. Verlagsanstalt. 
LóPEZ, François

1990 «Une autre approche de Sinapia». En: Jean Pierre Etienvre (coord.). Las utopias en el mundo bispánico: actas del coloquio celebrado en la Casa de Velázquez: Madrid: Casa de Velázquez, pp. 9-18.

MacCormack, Sabine

2002 «Conciencia y práctica social: pobreza y vagancia en España y el temprano Perú colonial». Revista andina, n. 35, julio, pp. 69-110.

Medina Rojas, Francisco de Borja

1999 «Blas Valera y la dialéctica 'exclusión-integración' del otro». Archivum Historicum Societatis Iesu, Periodicum semestre, año LXVIII, fasc. 136, julio-diciembre, pp. 229-268.

Mignolo, Walter

1995 The darker side of the Renaissance: Literacy, Territoriality, and Colonization. Ann Arbor: University of Michigan Press.

MurRa, John V.

2002 «Nos hacen mucha ventaja: percepción europea temprana de loslogros andinos». En: El Mundo Andino: Población, Medio Ambiente y Economía. Lima: Pontificia Universidad Católica del Perú e Instituto de Estudios Peruanos, pp. 25-40.

OlaecheA, Juan Bautista

1992 El mestizaje como gesta. Madrid: Mapfre.

ReINHARD, Wolfgang

1987 «Sprachbeherrschung und weltherrschaft. Sprache und Sprachwissenschaft in der europaïschen Expansion». En: Reinhard, Wolfgang (ed.). Humanismus und Neue Welt. Acta Humaniora. Bonn: VCH, pp. 1-36.

Rico, Francisco

1993 El Sueño Del Humanismo: De Erasmo a Petrarca. Madrid: Alianza Editorial. 
Rodríguez Carracido, José

1899 El P. José de Acosta y su importancia en la literatura española. Madrid: Sucesores de Rivadeneyra.

Rowe, John H.

1965 «The Renaissance Foundations of Anthropology». American Anthropologist, vol. 67, pp. 1-20.

1974 «Sixteenth and Sevententh Century Grammars». En: Dell Hymes (ed.). Studies in the History of Linguistic. Traditions and Paradigms. Bloomington; Londres: Indiana University Press, pp. 361-379.

Subramanyam, Sanjai

2006 «Sobre comparaciones y conexiones: notas sobre el estudio de los imperios ibéricos de Ultramar, 1490-1640». En: Roger Chartier y Antonio Feros (coords.). Europa, América y el mundo: tiempos históricos. Madrid: Marcial Pons, pp. 239-261.

VEGA, Garcilaso Inca de la

1991 Comentarios reales de los incas. 2 vols. Edición, índice analítico y glosario de Carlos Araníbar. México: Fondo de Cultura Económica. 